\title{
Pharmacokinetics and biodistribution of the cyclin-dependent kinase inhibitor -CR8- in mice
}

\author{
Hatem Sallam', Ibrahim El-Serafi' ${ }^{1}$, Laurent Meijer ${ }^{2}$ and Moustapha Hassan 1,3,4*
}

\begin{abstract}
Background: CR8 is a second generation inhibitor of cyclin-dependent kinases derived from roscovitine. CR8 was shown to be 50-100 fold more potent than roscovitine in inducing apoptosis in different tumor cell lines. In the present investigation, we have established an analytical method for the quantification of CR8 in biological samples and evaluated its bioavailability, biodistribution and pharmacokinetics in mice.
\end{abstract}

Methods: A liquid chromatography method utilizing UV-detection was used for the determination of CR8. CR8 was administered either orally $(100 \mathrm{mg} / \mathrm{kg})$ or i.v. $(50 \mathrm{mg} / \mathrm{kg})$ and the animals were sacrificed at different time points. Blood samples and organs were collected, after which the pharmacokinetic parameters were calculated for plasma and organs.

Results: CR8 was eluted at 5 minutes in the high performance liquid chromatography system used. The LLOQ detection was $0.10 \mu \mathrm{g} / \mathrm{ml}$ and linearity was observed within the $0.10-10 \mu \mathrm{g} / \mathrm{ml}$ range $\left(r^{2}>0.998\right)$. The accuracy and precision were $>86 \%$, while the recovery from plasma was $>95 \%$. CR8 was stable for 2 months at room temperature in both solution and plasma. CR8 pharmacokinetics was fitted to a two-compartment open model after oral administration and to a one compartment model after i.v. injection. The elimination half-life was about 3 hours. Organ exposure to CR8 (expressed as \% AUC organ vs. AUC plasma) was highest in liver (205\%), adipose tissue (188\%) and kidney (150\%) and low in bone marrow (30\%) and brain (15\%) as compared to plasma. The oral bioavailability of CR8 was found to be essentially $100 \%$.

Conclusions: We have developed a rapid and simple method for the analysis of CR8. CR8 pharmacokinetics pattern showed 100\% bioavailability, long half-life and limited distribution to brain and bone marrow, which may allow systemic exposure higher than the $I_{50}$ reported for cell death in tumor cell lines. CR8 displays favorable pharmacological properties and is therefore a good candidate for future clinical studies.

Keywords: Roscovitine, CR8, Pharmacokinetics, Cyclin-dependent kinase inhibitors, Kinase inhibitors, Biodistribution, HPLC

\section{Background}

Roscovitine is a selective cyclin-dependent kinase (CDK) $1,2,5,7$, and 9 inhibitor [1-4] shown to be effective against several tumors. At present, roscovitine is undergoing Phase II clinical trials in cancer patients (non-small cell lung cancer, nasopharyngeal cancer). The drug has limited side effects and toxicity compared to conventional chemotherapy [5]. However, roscovitine is shown to have a short elimination half-life and rapid metabolism, which

\footnotetext{
* Correspondence: moustapha.hassan@ki.se

'Experimental Cancer Medicine (ECM), Laboratory Medicine, Karolinska Institutet, 141 86, Stockholm, Sweden

${ }^{3}$ Experimental Cancer Medicine (ECM), Clinical Research Center, Novum, Karolinska University Hospital-Huddinge, 141 86, Stockholm, Sweden Full list of author information is available at the end of the article
}

leads to suboptimal exposure in clinical trials. Recently, 2(R)-(1-Ethyl-2-hydroxyethylamino)-6-(4-(2-pyridyl)benzyl)9-isopropylpurine (CR8; Figure 1) was introduced as a second generation cyclin-dependent kinase inhibitor derived from roscovitine [6]. CR8 is shown to be about 50-fold more potent compared to roscovitine in inducing apoptosis in different tumor cell lines including ALL and CLL [7].

Several in-vivo and in-vitro studies have reported promising results due to the high efficacy of CR8. Bukanov et al. show CR8 to be effective against autosomal dominant polycystic kidney disease by blocking the renal and hepatic cystogenesis in mice [8]. Another study reports that CR8 can induce apoptotic tumor cell death in the neuroblastoma cell line, which is one of the

\section{Biomed Central}

(c) 2013 Sallam et al.; licensee BioMed Central Ltd. This is an Open Access article distributed under the terms of the Creative Commons Attribution License (http://creativecommons.org/licenses/by/2.0), which permits unrestricted use, distribution, and reproduction in any medium, provided the original work is properly cited. 


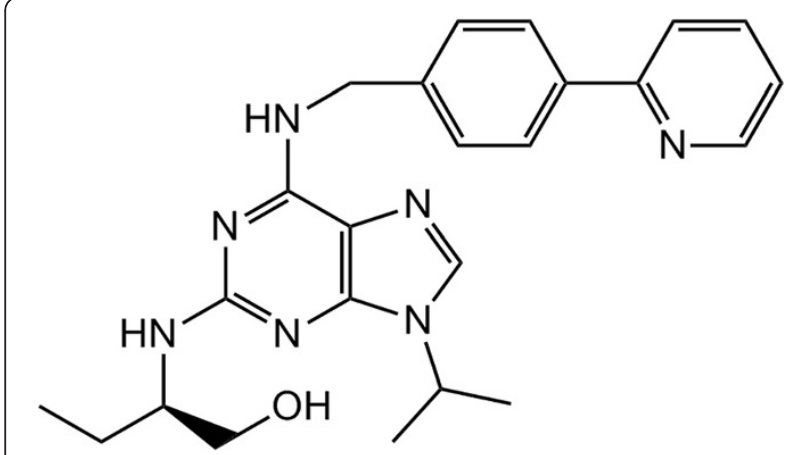

Figure 1 CR8: 2-(R)-(1-Ethyl-2-hydroxyethylamino)-6-(4-(2-pyridyl) benzyl)-9-isopropylpurine (CR8).

most frequent solid tumors in children [9]. CR8 is also proven to be a neuro-protector in experimental traumatic brain injury and has significantly reduced the lesion volume in rats subjected to moderate spinal cord contusion injury $[10,11]$. Moreover, CR8 is shown to increase the number of surviving neurons after spinal cord injury and to decrease the posttraumatic elevation of biochemical markers of apoptosis in an animal model [12].

Generally, the final effects of drugs in-vivo are influenced by many factors, such as systemic exposure, distribution in various organs, metabolism, lipophilicity, and protein binding. Bettayeb et al. show the optimal concentrations of CR8 needed to obtain a desirable pharmacological effect in-vitro in different cell lines to be about $0.7 \mu \mathrm{M}$ [7], which is far below that reported for roscovitine $(14.6 \mu \mathrm{M})$ [4].

Despite these results obtained in cell cultures, the pharmacokinetic profile of CR8 needs to be analyzed prior to further preclinical and possibly clinical investigations. In the present investigation we have established and validated an analytical method for the quantitative determination of CR8 according to standard bioanalytical guidelines. We have also investigated the pharmacokinetics profile and the tissue distribution of CR8 in mice. The present results are encouraging in terms of further development of CR8 as a drug candidate.

\section{Methods}

\section{Chemicals and reagents}

Tetrahydrofuran and methanol of high performance liquid chromatography (HPLC) grade were obtained from Merck (Darmstadt, Germany), Tween20 and dimethyl sulfoxide (DMSO) from Sigma-Aldrich (Stockholm, Sweden). All other reagents and solvents were of HPLC analytical grade. S-CR8 was dissolved in DMSO as a $75 \mathrm{mg} / \mathrm{ml}$ stock solution and was stored at $-20^{\circ} \mathrm{C}$. Serial dilutions were prepared from the main stock for the calibration curves, as quality control samples and for administration to mice. (R)-roscovitine and (S)-CR8 were synthesized as described previously [13].

\section{Instrumentation and chromatographic conditions}

The HPLC system consisted of a Gilson 234 auto-injector equipped with a $100 \mu \mathrm{l}$ loop, an LKB 2150 pump (Pharmacia inc., Sweden), an "LDC analytical spectromonitor 3200" UV-detector (USA) and a CSW 32 chromatography station integrator. Separation was performed on a Zorbax SB-CN column $(3.5 \mu \mathrm{m} \times 4.6 \mathrm{~mm} \times 150 \mathrm{~mm})$ from Agilent (USA), while the column was maintained at room temperature during analysis.

The mobile phase consisted of tetrahydrofuran: $25 \mathrm{mM}$ phosphate buffer $\mathrm{pH}=2.6$, ionic strength $=0.022$ (20:80, $\mathrm{v} / \mathrm{v})$. Flow rate was set at $0.9 \mathrm{ml} / \mathrm{min}$, running time at $8 \mathrm{~min}$ for standard curve and quality controls and at $15 \mathrm{~min}$ for animal samples to elute all the metabolites. Injection volume was $50 \mu \mathrm{l}$ and the UV wavelength used was $305 \mathrm{~nm}$. Standard curves were prepared from spiked pooled human plasma, and were linear in the range of $0.1-10 \mu \mathrm{g} / \mathrm{ml}$.

\section{Standard solutions and controls}

Pooled heparin plasma from healthy donors was obtained from the Blood Transfusion Center, Karolinska University Hospital. Serial standard dilutions in $50 \mathrm{mM}$ Hydrochloric acid were prepared from the stocks for the calibration curves and for the quality controls.

Working standard solutions of CR8 in plasma at 10, 8, $6,5,4,3,2,1,0.5,0.25$ and $0.1 \mu \mathrm{g} / \mathrm{ml}$ were prepared by adding $50 \mu \mathrm{l}$ from the standard stocks to $950 \mu \mathrm{l}$ plasma to reach $1 \mathrm{ml}$ containing the final concentrations. The calibrators were prepared on the day of each run.

Four quality control samples at concentrations of 0.75 , $1.5,3.5$ and $7.0 \mu \mathrm{g} / \mathrm{ml}$ were also prepared in triplicate and stored at room temperature, $+4^{\circ} \mathrm{C}$ and $-20^{\circ} \mathrm{C}$ for stability testing.

The quality control samples were repeated using mouse plasma in triplicate using the same concentrations as in human plasma.

\section{Sample preparation from plasma}

$70 \mu \mathrm{l}$ plasma was added to $140 \mu \mathrm{l}$ methanol and vortexed for $15 \mathrm{sec}$. Samples were centrifuged at $10000 \mathrm{~g}$ for $10 \mathrm{mi}-$ nutes, and $50 \mu \mathrm{l}$ from the supernatant were injected into the HPLC system.

\section{Bioanalytical method validation \\ Selectivity}

A selective method should involve no interference from endogenous compounds, metabolites and/or different degradation products related to the drug [14]. We confirmed that our method involved no such interference by running blank biological samples from untreated mice and mice receiving only the drug vehicle [15]. 


\section{Calibration curve}

A calibration curve was constructed from eight standard points of CR8 at concentrations ranging from 0.1 $10 \mu \mathrm{g} / \mathrm{ml}$, including lower limit of quantification (LLOQ). The peak areas of CR8 were plotted against the concentrations. Linearity was assessed by a weighted least-squares regression analysis and a correlation coefficient $\left(r^{2}\right)$ of 0.99 or better was deemed acceptable. The LLOQ was set as the lowest measurable concentration with acceptable accuracy and precision not more than $20 \%$ of the expected values [16].

\section{Precision and accuracy}

The precision of the method was defined as the percent relative standard deviation (\% SD) calculated from triplicate measurements [(standard deviation)/mean value] $\times$ 100. The accuracy was defined as the percent relative error (\% E) of the mean of the replicate measurements in relation to the theoretical values [(measured value nominal value)/nominal value $\times 100[16,17]$. Precision and accuracy were determined by analyzing quality control samples (QCs) prepared at four concentrations $(0.75,1.5,3.5$ and $7.0 \mu \mathrm{g} / \mathrm{ml})$ in pentaplicate on three consecutive days [18].

\section{Recovery}

Absolute recovery is defined as percentage of reference compound that is measured to the exact amount of compound added to a blank buffer [15]. Recovery was computed by comparing responses in triplicate of extracted low, middle and high QCs $(0.75,1.5$ and $7.0 \mu \mathrm{g} / \mathrm{ml}$, respectively) samples with those of extracted solvent to which CR8 has been added at the same nominal concentration [14].

Relative recovery is defined as percentage of the amount of drug measured from the plasma compared to the amount measured from pure solvent e.g. $50 \mathrm{mM}$ hydrochloric acid ( $\mathrm{HCl})$ [15]. The low, medium and high controls $(0.75,1.5$ and $7.0 \mu \mathrm{g} / \mathrm{ml}$, respectively) were prepared in pooled plasma and in $50 \mathrm{mM} \mathrm{HCl}$. Samples were run in triplicate and recovery was calculated as the percentage of (plasma peak area/methanol peak area) $\times 100$.

\section{Stability}

The stability of CR8 was determined in plasma samples using concentrations of $0.75,1.5,3.5$ and $7.0 \mu \mathrm{g} / \mathrm{ml}$ (in triplicate). The samples were kept at room temperature, $+4^{\circ} \mathrm{C}$ and $-20^{\circ} \mathrm{C}$ and analyzed twice weekly for 2 months. Peak areas of all the samples were compared to peak areas obtained at time zero.

\section{Animals}

All experiments in this study were approved by the Stockholm Southern Ethics Committee for Animal
Research and were conducted in accordance with the Animal Protection Law, the Animal Protection Regulation and the Regulation for the Swedish National Board for Laboratory Animals.

Female BALB/c mice 8-10 weeks old and weighing 18-21 g were obtained from Scanbur, Sollentuna, Sweden. The mice were allowed to acclimatize to their surroundings for one week before starting treatment. The mice were fed pelleted food and water ad libitum.

CR8 was dissolved in DMSO: $50 \mathrm{mM} \mathrm{HCl}(10: 90 \mathrm{v} / \mathrm{v})$. The first group of mice received i.v. doses of CR8 (50 $\mathrm{mg} / \mathrm{kg}$ body weight), the second received oral doses of CR8 (100 mg/kg body weight) and three control mice received vehicle alone. Three mice were sacrificed at each time point and blood samples were collected by cardiac puncture into heparinized tubes at 10, 20, 30, $60 \mathrm{~min}, 2,4,6,8 \mathrm{~h}$ post administration. Blood samples were centrifuged immediately after collection at $3000 \mathrm{~g}$ for $5 \mathrm{~min}$ at $4^{\circ} \mathrm{C}$ and the plasma was prepared as mentioned previously. Supernatants were collected and all samples were frozen at $-20^{\circ} \mathrm{C}$ directly after preparation until further analysis by HPLC. Other organs including liver, spleen, kidneys, brain, adipose tissue and lungs were removed, washed and snap frozen immediately in liquid nitrogen. Bone marrow was flushed from both femurs and mononuclear cells were counted and frozen. The samples were stored at $-20^{\circ} \mathrm{C}$ to avoid any metabolic activity.

\section{Tissue sample preparation}

Samples from different organs were homogenized by probe sonication in sodium perborate (PBS) (1:3 - 1:5 w:v) for $2 \mathrm{~min}$ and vortexed for $1 \mathrm{~min} .100 \mu \mathrm{l}$ of the homogenate was added to $200 \mu \mathrm{l}$ methanol, vortexed for $1 \mathrm{~min}$ and centrifuged at $10000 \mathrm{~g}$ for $10 \mathrm{~min} .50 \mu \mathrm{l}$ of the supernatant were injected into the HPLC system.

Femurs were removed and cleaned; bone marrow was flushed with $0.3 \mathrm{ml}$ of PBS and single cell suspension was prepared by gentle flushing through needle and syringe.

Nucleated cells were counted using Türk solution and bone marrow was stored at $-20^{\circ} \mathrm{C}$ until assay.

Quality control samples were run together with the corresponding mouse samples in duplicate.

\section{Pharmacokinetics}

Parameters including distribution volume of the central compartment, elimination rate constant, plasma maximum concentration and micro constants were estimated. Clearance $(\mathrm{Cl})$ and distribution volume at the steady state were calculated from the primary parameters. The plasma concentration versus time curves (AUC) were calculated from the model derived parameters, and the elimination half-lives were calculated from the slope of the terminal elimination phase. Bone marrow 
data were derived after adjustment of concentrations to $10^{9}$ cells (= approx. $1 \mathrm{~g}$ of tissue). The pharmacokinetic modeling was performed using WinNonlin version 5.2 (Pharsight, USA).

Oral bioavailability $(\mathrm{F})$ defined as the fraction of the oral administered dose of CR8 that reaches the systemic circulation was calculated according to the following formula:

$$
F=\frac{[A U C]_{p o} * \operatorname{dose}_{I V}}{[A U C]_{I V} * \text { dose }_{p o}}
$$

\section{Calculations and statistics}

The peak areas of CR8 were plotted versus the corresponding nominal concentrations of the standards, and the standard curve was calculated by linear regression. CR8 concentrations in mouse plasma, organs and quality control samples were calculated from the resulting curves. All values are presented as mean \pm S.D.

\section{Results}

Analysis of CR8

A precise and accurate method was developed to detect the drug in plasma and tissue samples in order to investigate the pharmacokinetics of CR8. CR8 is a lipophilic compound; however, due to the presence of the 2-pyridyl ring attached to the benzyl ring, its lipophilicity is lower than that of the parent analogue roscovitine. DMSO was found to be a suitable solvent for very high concentrations of CR8, and $50 \mathrm{mM} \mathrm{HCl}$ was found to be a suitable solvent for standard concentrations. Protein precipitation is the simplest approach for removing most proteins from biological samples. Methanol was shown to be better than acetonitrile in deproteinizing the plasma and extracting CR8 due to lower number of interfering peaks.

\section{UV absorbance}

UV absorbance was determined by running a UV-IVIS spectrum scan of CR8 dissolved in $50 \mathrm{mM} \mathrm{HCl}(10 \mu \mathrm{g} /$ $\mathrm{ml})$. No interference in the absorption range was detected. The scan revealed good absorption in the UV $210 \mathrm{~nm}$ $310 \mathrm{~nm}$ wavelength ranges, and $305 \mathrm{~nm}$ was selected as the best measurement wavelength to ensure good selectivity and good sensitivity with a wide range of linear response for construction of the standard curves.

\section{Chromatograms and specificity}

The CR8 retention time was around $5.26 \pm 0.3 \mathrm{~min}$. Selectivity was confirmed by the absence of significant interfering peaks from endogenous compounds in the blank plasma at this retention time (Figure 2). Also, no interference was found from endogenous compounds in the mouse plasma and tissue samples compared to control samples (Figure 3).

\section{Linearity and limit of quantification}

The calibration curve was linear within the ranges of $0.1 \mu \mathrm{g} / \mathrm{ml}-10 \mu \mathrm{g} / \mathrm{ml}$, and had a correlation coefficient $\left(r^{2}\right) \geq 0.9987(n=6)$. The lower limit of quantification for CR8 was $0.1 \mu \mathrm{g} / \mathrm{ml}$ in human plasma. The precision and accuracy at LLOQ were 3.7 and $13.3 \%$, respectively.

\section{Accuracy and precision}

The precision and accuracy between and within batch were always below 13\% from the nominal values in all cases. Precision and accuracy fulfilled the standard guiding principles for validation of bioanalytical methods, i.e. < $15 \%$ for QCs both between batches and within batches and $<20 \%$ for LLOQ $[14,16,17,19,20]$. No differences were observed between mouse and human plasma concerning concentrations in QCs (Table 1).

\section{Recovery}

The absolute recovery of CR8 in plasma was $97 \pm 6 \%, 95 \pm$ $5.0 \%$ and $98 \pm 4 \%$ at the concentrations of $0.75,1.5$ and $7.0 \mu \mathrm{g} / \mathrm{ml}$, respectively, while the relative recoveries of the drug for the same concentrations in plasma compared to that obtained from $50 \mathrm{mM} \mathrm{HCl}$ were $99 \pm 3,103 \pm 2$ and $96+5 \%$, respectively. The recovery from plasma was almost completely with low variability. Consequently, plasma could be a suitable matrix for the regular calibrations needed to analyze patient/animal materials in future invivo experiments [21].

\section{Stability}

The drug proved to be highly stable after 2 months at room temperature, $+4^{\circ} \mathrm{C}$ or $-20^{\circ} \mathrm{C}$, with no significant decrease in the concentration of the QC samples (stability found to be approximately $97 \pm 3.5 \%$ ).

\section{CR8 Metabolites}

Five CR8 metabolites were separated and found to absorb $\mathrm{UV}$ at the same wavelength as CR8. These metabolites were named M1-M5 and appeared in the chromatogram in the following order: M1 at 4.23 minutes, M2 at 5.79 minutes, M3 at 8.13 minutes, M4 at 9.95 minutes and M5 at 11.81 minutes (Figure 4). The first and fifth metabolites (M1 \& M5) appeared rapidly with maximum concentration at 20 minutes and slowly disappeared until 8 hours. The metabolite M4 increased by time to reach maximum concentration at 60 minutes then disappeared. The metabolites M2 and M3 increased and accumulated with time until 8 hours post administration (Figure 4).

\section{Pharmacokinetics of CR8}

To conduct the CR8 pharmacokinetic studies, a simple HPLC-UV method for the determination of CR8 in human plasma was developed and validated. The pharmacokinetics of CR8 were then investigated in mice and 


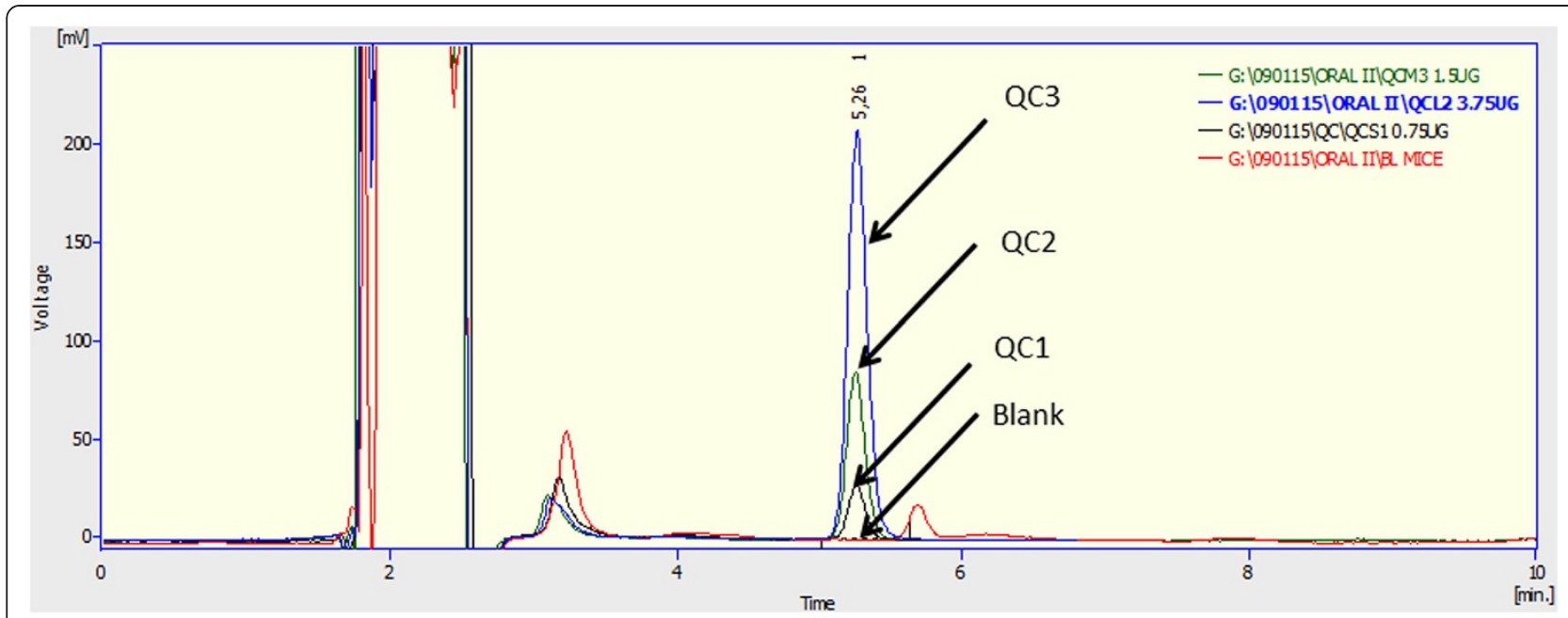

Figure 2 Quality control samples in human plasma: HPLC chromatograms of blank samples and plasma containing CR8 (QCs) at concentrations of $1.5,3.75$ and $10.75 \mu \mathrm{g} / \mathrm{mL}$.

found to fit a two-compartment open model after oral administration and a one compartment bolus model after i.v. administration (Figure 5) using Gauss-Newton criteria.

The CR8 AUC was about $100 \mu \mathrm{g} . \mathrm{hr} / \mathrm{ml}$ when $100 \mathrm{mg} /$ $\mathrm{kg}$ was administered orally and about $45 \mu \mathrm{g} . \mathrm{hr} / \mathrm{ml}$ when $50 \mathrm{mg} / \mathrm{kg}$ was administered intravenously. However, the estimated $C_{\max }$ was over $100 \mu \mathrm{g} / \mathrm{ml}$ after i.v. administration, which is 4 fold higher compared to that observed after oral administration (Table 2).

Absorption and distribution were rapid and the maximum concentrations were found at $30 \mathrm{~min}$. Most importantly, the elimination half-life was estimated to be about 3 hours.

Exposure to concentrations much higher than the reported average $\mathrm{IC}_{50}$ value $(0.7 \mu \mathrm{M})$ [7] was found to last more than 8-10 hours.

The oral bioavailability of CR8 was calculated to be $108 \pm 9 \%$.

\section{Biodistribution of CR8}

CR8 was widely distributed into all tissues, and the time - concentration curves (AUCs) were fitted to one compartment for all tissues (Table 3).

Higher exposure was found in the liver (the tissue/plasma exposure ratio was 200\%), adipose tissue (180\%) and kidneys (150\%) compared to that observed as systemic exposure in plasma. Lung and spleen showed a tissue/plasma ratio of $80 \%$ and $50 \%$, respectively (Figure 6) as compared to plasma.

\section{CR8 distribution to the bone marrow}

Exposure to CR8 was about $30 \%$ in bone marrow compared to in plasma when the concentrations were normalized to tissue weight/g (Figure 6).

This exposure is higher than that reported as $\mathrm{IC}_{50}$ required for the elimination of leukemic cell lines in about $6 \mathrm{~h}$ (data not shown).

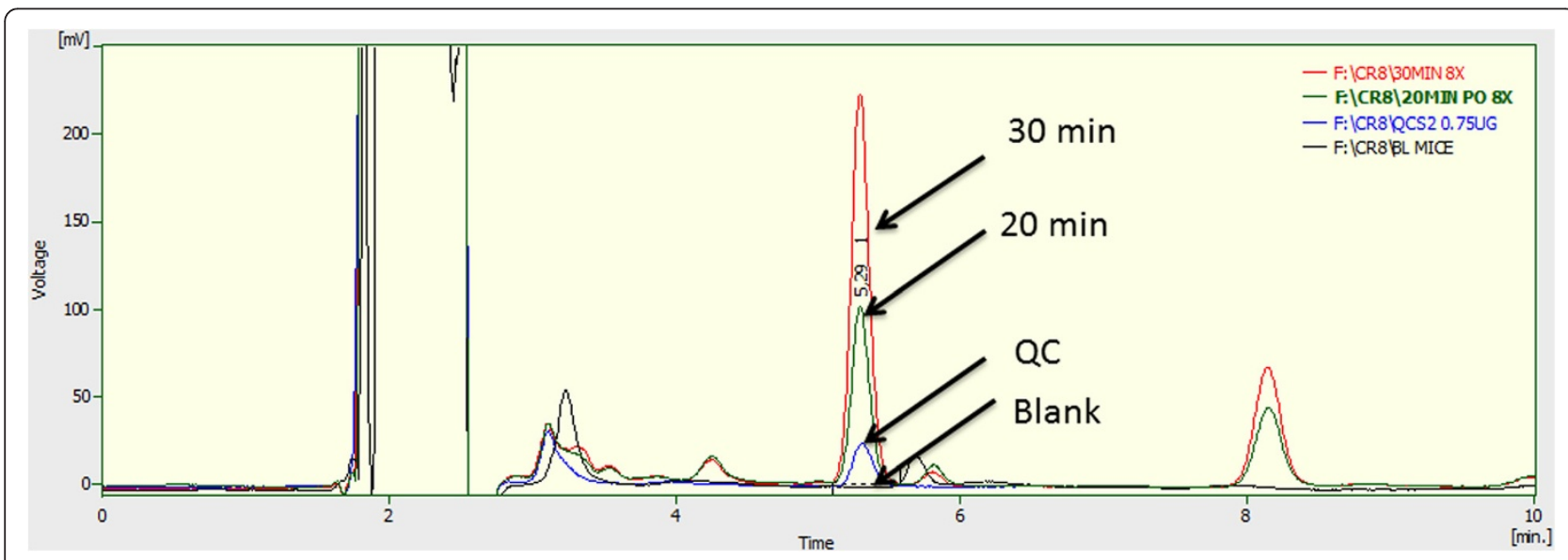

Figure 3 HPLC chromatograms of mouse plasma: The chromatograms contain blank sample, QC (0.75 $\mu \mathrm{g} / \mathrm{mL})$ and CR8 at 20 and $30 \mathrm{~min}$ after oral administration. 
Table 1 Precision and accuracy of the CR8 analysis ( $n=3-5$ each)

\begin{tabular}{|c|c|c|c|c|c|c|}
\hline Concentration $(\mu \mathrm{g} / \mathrm{ml})$ & & Precision (\%) & & & Accuracy (\%) & \\
\hline \multicolumn{7}{|l|}{ Between batch } \\
\hline $0.1(L L O Q)$ & & 3.7 & & & -13.3 & \\
\hline $0.75(\mathrm{QC} 1)$ & & 7.7 & & & -2.0 & \\
\hline $1.5(\mathrm{QC2})$ & & 6.9 & & & -3.8 & \\
\hline $3.5(\mathrm{QC} 3)$ & & 4.9 & & & -4.4 & \\
\hline $7.0(\mathrm{QC4})$ & & 3.3 & & & -5.3 & \\
\hline Within batch & Batch1 & Batch2 & Batch3 & Batch1 & Batch2 & Batch3 \\
\hline $\mathbf{0 . 1}(\mathrm{LLOQ})$ & 4.2 & 3.4 & 4.8 & -16 & -15.4 & -8.5 \\
\hline $0.75(\mathrm{QC} 1)$ & 1.4 & 1.8 & 1.9 & 5.5 & -12.9 & -1.2 \\
\hline $1.5(\mathrm{QC} 2)$ & 1.5 & 1.7 & 0.8 & 4.3 & -6.7 & 3.0 \\
\hline $3.5(\mathrm{QC} 3)$ & 0.2 & 0.6 & 1.1 & -9.1 & -9.9 & -0.6 \\
\hline $7.0(\mathrm{QC4})$ & 0.8 & 2 & 1.3 & -3.5 & -7.4 & -4.1 \\
\hline
\end{tabular}

\section{CR8 distribution to the brain}

CR8 was found to pass the blood-brain barrier (BBB) and the concentration in the brain was about $15 \%$ of that in plasma. Despite this low tissue/plasma ratio, the concentration reached a value above the reported CDK5/p25 and casein kinase 1 (CK1) inhibitory $\mathrm{IC}_{50}$ values for more than 6 hours.

\section{Discussion}

Recently, the tri-substituted purine CR8 was introduced as a selective second generation CDK inhibitor analogue of roscovitine [6,7]. In-vitro studies have shown that CR8 is 2-4 fold more potent as a CDK inhibitor and 50-100 fold more cytotoxic in tumor cell lines [7]. However, this enhanced in-vitro activity of CR8 needs to be confirmed in-vivo in animal models prior to further development toward clinical trials in patients. The future investigation and development of this purine requires an accurate analytical method for the quantitative determination of its pharmacokinetics pattern. In the present investigation we have developed and validated a new analytical method for the determination of CR8 in plasma and tissue samples. Our data showed that the method is selective and accurate. The acceptance criteria for the method validation are well in accordance with internationally accepted criteria [15,18]. Moreover, the volume required for the analysis is only $50 \mu \mathrm{l}$ of plasma, a favorable factor when considering plasma sampling from small laboratory animals.

The present method was employed for studying the pharmacokinetics and biodistribution of the drug in mice. It is of great importance to use a single, suitable analytical method for both pre-clinical and clinical studies of newly introduced drugs, such as CDK inhibitors, that are promising for the treatment of several diseases including cancer. One important factor is that the

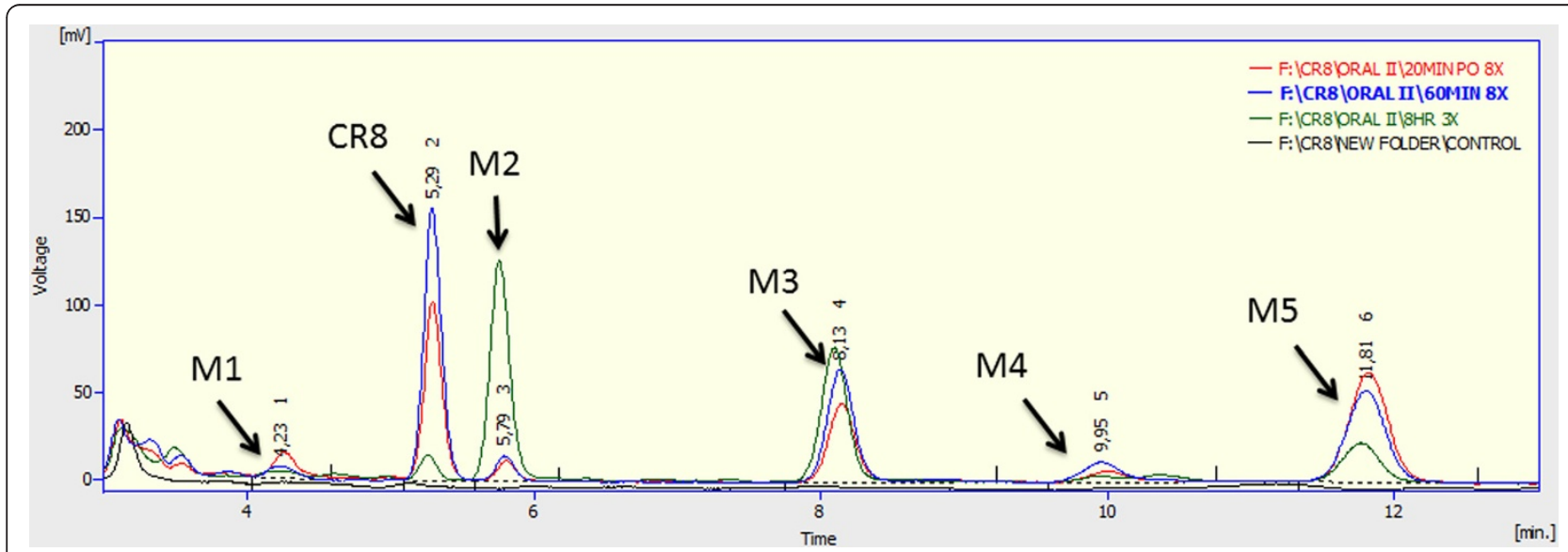

Figure 4 HPLC chromatograms of CR8 and its metabolites. Chromatograms showing CR8 and its five metabolites at different time points after oral administration, (red) 20 minutes post administration, (blue) 60 minutes post administration, (green) 8 hours post administration, (black) blank. 


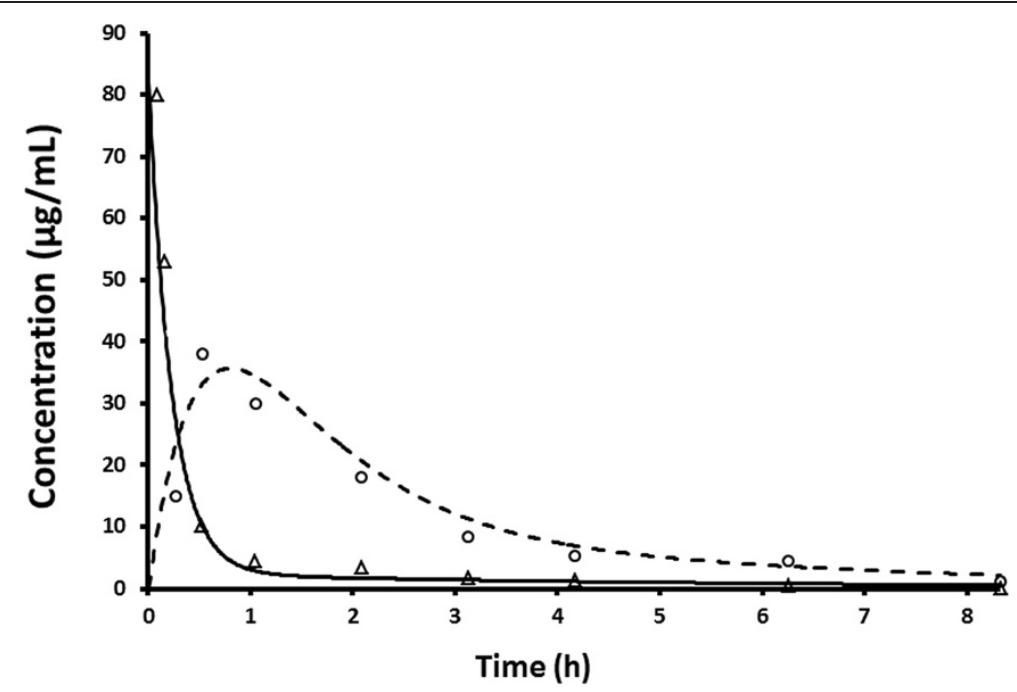

Figure 5 Time-plasma concentration curve after PO and IV CR8 to the mouse. Plasma time concentration curve after the oral administration of $100 \mathrm{mg} / \mathrm{kg}$ CR8 where the dashed line is the estimated two compartment model while the open circles are the observed concentrations. The solid line is the estimated one compartment model after the iv administration of $50 \mathrm{mg} / \mathrm{kg}$ CR8, while open triangles represent the measured concentrations.

present method does not require work up procedures, a favorable factor for clinical studies where large numbers of samples are generated and speed of analysis is important.

The pharmacokinetics profile (especially the oral bioavailability and the elimination half-life) constitutes a set of critical factors, strongly influencing whether CR8 should enter preclinical and clinical trials as an antitumor agent. Good oral absorption and appropriate biological half-life allowing enough exposure to the drug to produce pharmacological activity and anti-tumor effect [22], and sufficient elimination allowing minimal toxicity, are indeed crucial for further development of an anti-cancer drug.

Table 2 PK parameters of CR8 following single oral administration at $100 \mathrm{mg} / \mathrm{kg}$ and i.v. bolus administration of $50 \mathrm{mg} / \mathrm{kg}$

\begin{tabular}{lcc}
\hline PK parameters & Oral & i.v. \\
\hline AUC $(h . \mu g / m l)$ & $96.34 \pm 10.53$ & $44.35 \pm 3.3$ \\
$T a(h)$ & $1.3 \pm 0.43$ & $0.11 \pm 0.01$ \\
$T \beta(h)$ & $3.1 \pm 0.35$ & $2.95 \pm 0.11$ \\
$C_{\max }(\mu \mathrm{g} / \mathrm{ml})$ & $34.3 \pm 1.94$ & $163.9 \pm 0.25$ \\
$V s s(\mathrm{ml})$ & $21 \pm 3$ & $44 \pm 4$ \\
$\mathrm{CL}(\mathrm{ml} / \mathrm{h})$ & $21 \pm 2$ & $23 \pm 2$ \\
Bioavailability & $\left(96.43^{*} 50\right) /\left(44.35^{*} 100\right)^{*} 100=108 \%$
\end{tabular}

AUC: Area under time plasma concentration curve.

Ta: First elimination half-life.

$\mathrm{T} \beta$ : Terminal elimination half-life.

$C_{\text {max }}$ : Maximum reached concentration.

Vss: Distribution volume at steady state.

$\mathrm{CL}$ : Clearance.
Roscovitine, which was introduced as one of the earliest CDK inhibitors, is at the present time undergoing phase II clinical trials in advanced non-small cell lung cancer and nasopharyngeal cancers [23]. Roscovitine was shown to have good oral bioavailability and low systemic toxicity profile $[5,24]$. However, the anti-tumor responses observed were modest, most probably a consequence of the drug's short half-life and rapid metabolism to inactive metabolites [25]. Generally, exposure to the drugs is an important factor in the exertion of their antitumor activity. It has been shown that the optimum effect of roscovitine and the closely related analogue, N\&N1, on tumor cell lines occurs after $8-16$ hours of exposure [26-28]. The systemic exposure to roscovitine (expressed as AUC in plasma) in adult animals and humans did not allow a plasma concentration to be maintained above the reported anti-tumor $\mathrm{IC}_{50}$ (15$17 \mu \mathrm{M})$ for more than 1-2 hours, even when the maximum tolerated doses were administered [5]. The only exception was in young rats, most probably due to immature metabolism [29]. The present results showed that the systemic exposure expressed as plasma AUC of CR8 (after single dose administration of $100 \mathrm{mg} / \mathrm{kg}$ ) was, for 10 hours, far higher than the anti-tumor $\mathrm{IC}_{50}$ values found in-vitro $(0.3 \mu \mathrm{g} / \mathrm{mL})$. Thus, second generation analogues of roscovitine might, in addition to increased cell potency, solve the problem of insufficient exposure observed in roscovitine. The higher systemic exposure might in part be explained by the longer half-life (approximately $3 \mathrm{~h}$ ) found in female BALB/c mice in the present study. In this respect CR8 differs from both roscovitine [27,30] and its close analogue N\&N1 [26], 
Table 3 Pharmacokinetic parameters of CR8 in different organs following single oral administration of $100 \mathrm{mg} / \mathrm{kg}$

\begin{tabular}{lcccccccc}
\hline & Plasma & Liver & Adipose tissue & Kidney & Lung & Spleen & Bone marrow & Brain \\
\hline AUC $(\mu \mathrm{g} . \mathrm{hr} / \mathrm{g})$ & 96 & 197 & 181 & 145 & 77 & 40 & 34 & 14 \\
Beta-HL $(\mathrm{hr})$ & 3.10 & 2.43 & 2.40 & 2.62 & 2.58 & 2.60 & 1.98 & 2.12 \\
Cmax $(\mu \mathrm{g} / \mathrm{ml})$ & 34.3 & 52.4 & 48.7 & 36.0 & 19.3 & 27.7 & 10.6 \\
CL/F & 21.0 & 10.2 & 11.1 & 13.8 & 26.2 & 20.0 & 29.5 & 14.1 \\
V2/F & 21.0 & 35.8 & 38.2 & 52.2 & 96.7 & 74.5 & 84.5 \\
\hline
\end{tabular}

which both have a reported half-life of approximately 1 hour when given i.v. at the same dosage.

CR8 was found to have approximately $100 \%$ oral bioavailability, which means the drug is suitable for oral route intake and that the first pass effect is negligible.

CR8 distributed rapidly to all the peripheral tissues. The highest tissue distribution, as compared to plasma AUC, was found mainly in elimination organs, namely liver (200\%) and kidneys (200\%). These results encourage the hope that CR8 could perhaps be used to treat liver and kidney tumors, since it was found to induce apoptotic cell death in both hepatic and renal tumor cell lines [7]. Moreover, CR8 showed high distribution to the adipose tissue (180\%) compared to that found in plasma, a factor that should be considered in dose scheduling in obese patients.

Surprisingly, CR8 showed higher distribution to the bone marrow (30\%) compared to roscovitine, which was shown to pass the bone marrow barrier by only $1.5 \%$ [28] while the biodistribution of CR8 in the spleen was

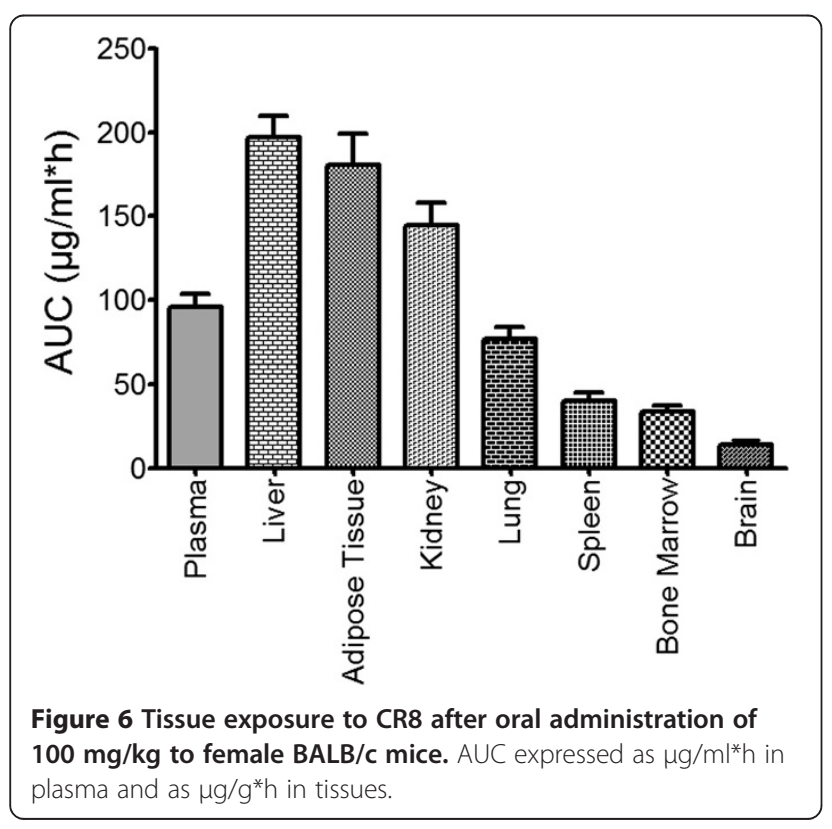

about $40 \%$. Moreover, the cytotoxicity of CR8 against leukemic cell lines has been reported [7]. Altogether, these results suggest the possible use of CR8 in treating leukemia and lymphomas. However, the high biodistribution to the bone marrow may cause myelosuppression, which was not detected in roscovitine [28]. Further studies are currently ongoing in our laboratory to explore the cytotoxic effect of CR8 on normal hematopoietic progenitors. Moreover, we have observed five different metabolites with different polarities that have appeared with different kinetics throughout the CR8 kinetics. Urgent studies are needed to identify and quantify these metabolites, and to establish their pharmacological activates and toxicities.

In the present study, we have also shown that CR8 passes the BBB (concentration reached is $15 \%$ of that in plasma) compared to that reported for roscovitine (30\%). This exposure of the brain to CR8 is nevertheless higher than that required for inhibition of its neuronal targets like CDK5 and CK1 ( $\mathrm{IC}_{50}$ values: $0.12 \mu \mathrm{M}$ and $0.61 \mu \mathrm{M}$, respectively) [7]. This fact may benefit the drug during further studies in neurodegenerative animal models and brain tumor models.

\section{Conclusions}

We have developed and validated a simple, fast and selective quantitative analytical method which allowed us to analyze the pharmacokinetic profile and tissue distribution of the second generation CDK inhibitor CR8. CR8 was shown to have $100 \%$ bioavailability and longer half-life compared to roscovitine, which may allow higher systemic exposure than the $\mathrm{IC}_{50}$ values for tumor cell death induction. The drug passes the BBB at a level sufficient to reach concentrations able to inhibit neuronal kinase targets. Bone marrow exposure was about $30 \%$ of that found as systemic exposure, a concentration potentially sufficient to eliminate leukemic cells. However, further studies are required to determine the myelosuppressive effect and hematotoxicity of CR8. The present study thus shows favorable pharmacokinetics properties of CR8 compared to its parent analogue roscovitine, encouraging further in-vivo studies and consideration of CR8 as a drug candidate. 


\section{Competing interests}

The authors declare that they have no competing interests.

\section{Authors' contributions}

HS: carried out the experiments and drafted the manuscript. I EIS: performed the quality controls, and drafted the manuscript. LM: Provided the drug, drafted the manuscript. $\mathrm{MH}$ : Designed the experiment. All authors read and approved the final manuscript.

\section{Acknowledgments}

This investigation was supported by grants from the Swedish Childhood Cancer Society (Barncancerfonden) and the Swedish Cancer Foundation (Cancerfonden). This research was also supported by grants from the "Cancéropole Grand-Ouest" (LM), the "Association France-Alzheimer Finistère" (LM), the "Ligue Nationale contre le Cancer (Comité Grand-Ouest)" (LM) and the Polycystic Kidney Disease Foundation (PKD Foundation, USA \& France) (LM) and "Association pour la Recherche sur le Cancer" (ARC-1092).

\section{Author details}

${ }^{1}$ Experimental Cancer Medicine (ECM), Laboratory Medicine, Karolinska Institutet, 141 86, Stockholm, Sweden. ${ }^{2}$ C.N.R.S., 'Protein Phosphorylation and Human Disease' Group, C.N.R.S., Station Biologique, B.P. 74, 29682Roscoff cedex, Bretagne, France. ${ }^{3}$ Experimental Cancer Medicine (ECM), Clinical Research Center, Novum, Karolinska University Hospital-Huddinge, 141 86, Stockholm, Sweden. ${ }^{4}$ ECM, KFC, Karolinska University Hospital, 141 86, Stockholm, Sweden.

Received: 10 July 2013 Accepted: 26 September 2013 Published: 30 September 2013

\section{References}

1. Bach S, Knockaert M, Reinhardt J, Lozach O, Schmitt S, Baratte B, Koken M, Coburn SP, Tang L, Jiang T, et al: Roscovitine targets, protein kinases and pyridoxal kinase. J Biol Chem 2005, 280:31208-31219.

2. Meijer L, Borgne A, Mulner O, Chong JP, Blow JJ, Inagaki N, Inagaki M, Delcros JG, Moulinoux JP: Biochemical and cellular effects of roscovitine, a potent and selective inhibitor of the cyclin-dependent kinases cdc2, cdk2 and cdk5. Eur JBiochem 1997, 243:527-536.

3. Meijer $L$, Raymond $E$ : Roscovitine and other purines as kinase inhibitors. From starfish oocytes to clinical trials. Acc Chem Res 2003, 36:417-425.

4. Meijer LBK, Galons H: Roscovitine (CYC202, Seliciclib). In Monographs on Enzyme Inhibitors. CDK Inhibitors and their Potential as Anti-Tumor Agents. Edited by Smith PJ, Yue E. Boca Raton, FL, USA: CRC Press, Taylor \& Francis; 2006.

5. Benson C, White J, De Bono J, O'Donnell A, Raynaud F, Cruickshank C, McGrath H, Walton M, Workman P, Kaye S, et al: A phase I trial of the selective oral cyclin-dependent kinase inhibitor seliciclib (CYC202; RRoscovitine), administered twice daily for 7 days every 21 days. $\mathrm{Br} J$ Cancer 2007, 96:29-37.

6. Oumata N, Bettayeb K, Ferandin Y, Demange L, Lopez-Giral A, Goddard ML, Myrianthopoulos V, Mikros E, Flajolet M, Greengard P, et al: Roscovitinederived, dual-specificity inhibitors of cyclin-dependent kinases and casein kinases 1. J Med Chem 2008, 51:5229-5242.

7. Bettayeb K, Oumata N, Echalier A, Ferandin Y, Endicott JA, Galons H, Meijer $\mathrm{L}: \mathrm{CR} 8$, a potent and selective, roscovitine-derived inhibitor of cyclindependent kinases. Oncogene 2008, 27:5797-5807.

8. Bukanov NO, Moreno SE, Natoli TA, Rogers KA, Smith LA, Ledbetter SR, Oumata N, Galons H, Meijer L, Ibraghimov-Beskrovnaya O: CDK inhibitors Rroscovitine and S-CR8 effectively block renal and hepatic cystogenesis in an orthologous model of ADPKD. Cell Cycle 2012, 11:4040-4046.

9. Bettayeb K, Baunbaek D, Delehouze C, Loaec N, Hole AJ, Baumli S, Endicott JA, Douc-Rasy S, Benard J, Oumata N, et al: CDK inhibitors roscovitine and CR8 trigger Mcl-1 down-regulation and apoptotic cell death in neuroblastoma cells. Genes Cancer 2010, 1:369-380.

10. Kabadi SV, Stoica BA, Hanscom M, Loane DJ, Kharebava G, Murray li MG, Cabatbat RM, Faden Al: CR8, a selective and potent CDK inhibitor, provides neuroprotection in experimental traumatic brain injury. Neurotherapeutics 2012, 9:405-421.

11. Wu J, Pajoohesh-Ganji A, Stoica BA, Dinizo M, Guanciale K, Faden Al: Delayed expression of cell cycle proteins contributes to astroglial scar formation and chronic inflammation after rat spinal cord contusion. $J$ Neuroinflammation 2012, 9:169.

12. Wu J, Kharebava G, Piao C, Stoica BA, Dinizo M, Sabirzhanov B, Hanscom M, Guanciale K, Faden Al: Inhibition of E2F1/CDK1 pathway attenuates neuronal apoptosis in vitro and confers neuroprotection after spinal cord injury in vivo. PLoS One 2012, 7:e42129.

13. Oumata N, Ferandin Y, Meijer L, Galons H: Practical synthesis of roscovitine and CR8. Org Process Res Dev 2009, 13:641-644.

14. Bressolle F, Bromet-Petit M, Audran M: Validation of liquid chromatographic and gas chromatographic methods. Applications to pharmacokinetics. J Chromatogr B Biomed App/ 1996, 686:3-10.

15. Shah VP, Midha KK, Dighe S, McGilveray IJ, Skelly JP, Yacobi A, Layloff T, Viswanathan CT, Cook CE, McDowall RD: Analytical methods validation: bioavailability, bioequivalence and pharmacokinetic studies. Conference report. Eur J Drug Metab Pharmacokinet 1991, 16:249-255.

16. Hartmann C, Smeyers-Verbeke J, Massart DL, McDowall RD: Validation of bioanalytical chromatographic methods. J Pharm Biomed Anal 1998, 17:193-218.

17. Karnes HT, March C: Precision, accuracy, and data acceptance criteria in biopharmaceutical analysis. Pharm Res 1993, 10:1420-1426.

18. Shah VP, Midha KK, Findlay JW, Hill HM, Hulse JD, McGilveray IJ, McKay G, Miller KJ, Patnaik RN, Powell ML, et al: Bioanalytical method validation-a revisit with a decade of progress. Pharm Res 2000, 17:1551-1557.

19. Karnes HT, March C: Calibration and validation of linearity in chromatographic biopharmaceutical analysis. J Pharm Biomed Anal 1991 9:911-918.

20. Karnes HT, Shiu G, Shah VP: Validation of bioanalytical methods. Pharm Res 1991, 8:421-426.

21. Midha KK, Rawson MJ, Hubbard JW: Individual and average bioequivalence of highly variable drugs and drug products. J Pharm Sci 1997, 86:1193-1197.

22. Lin JH, Lu AY: Role of pharmacokinetics and metabolism in drug discovery and development. Pharmacol Rev 1997, 49:403-449.

23. Fischer PM, Gianella-Borradori A: Recent progress in the discovery and development of cyclin-dependent kinase inhibitors. Expert Opin Investig Drugs 2005, 14:457-477.

24. de la Motte S, Gianella-Borradori A: Pharmacokinetic model of Rroscovitine and its metabolite in healthy male subjects. Int J Clin Pharmacol Ther 2004, 42:232-239.

25. McClue SJ, Stuart I: Metabolism of the trisubstituted purine cyclindependent kinase inhibitor seliciclib (R-roscovitine) in vitro and in vivo. Drug Metab Dispos 2007, 36(3):561-70.

26. Bettayeb K, Sallam H, Ferandin Y, Popowycz F, Fournet G, Hassan M, Echalier A, Bernard P, Endicott J, Joseph B, Meijer L: N-\&-N, a new class of cell death-inducing kinase inhibitors derived from the purine roscovitine. Mol Cancer Ther 2008, 7:2713-2724.

27. Raynaud FI, Whittaker SR, Fischer PM, McClue S, Walton MI, Barrie SE, Garrett $M D$, Rogers $P$, Clarke SJ, Kelland LR, et al: In vitro and in vivo pharmacokinetic-pharmacodynamic relationships for the trisubstituted aminopurine cyclin-dependent kinase inhibitors olomoucine, bohemine and CYC202. Clin Cancer Res 2005, 11:4875-4887.

28. Song H, Vita M, Sallam H, Tehranchi R, Nilsson C, Siden A, Hassan Z: Effect of the Cdk-inhibitor roscovitine on mouse hematopoietic progenitors in vivo and in vitro. Cancer Chemother Pharmacol 2007, 60:841-849.

29. Sallam H, Jimenez P, Song H, Vita M, Cedazo-Minguez A, Hassan M: Agedependent pharmacokinetics and effect of roscovitine on Cdk5 and Erk1/2 in the rat brain. Pharmacol Res 2008, 58:32-37.

30. Nutley BP, Raynaud FI, Wilson SC, Fischer PM, Hayes A, Goddard PM, McClue SJ, Jarman M, Lane DP, Workman P: Metabolism and pharmacokinetics of the cyclin-dependent kinase inhibitor R-roscovitine in the mouse. Mol Cancer Ther 2005, 4:125-139.

doi:10.1186/2050-6511-14-50

Cite this article as: Sallam et al:: Pharmacokinetics and biodistribution of the cyclin-dependent kinase inhibitor -CR8- in mice. BMC Pharmacology and Toxicology 2013 14:50. 